\title{
Understanding the impact of Mycoplasma ovipneumoniae in domestic sheep
}

\begin{tabular}{|c|c|c|}
\hline $\begin{array}{l}\text { ve } \\
\text { ck } \\
\text { ase } \\
\text { ng } \\
\\
\text { gger } \\
\text { m } \\
\text { ur } \\
\text { ince }\end{array}$ & $\begin{array}{l}\text { eople rear domestic sheep for a } \\
\text { wide variety of reasons including } \\
\text { as a primary occupation producing } \\
\text { meat and fibre commodities, producing } \\
\text { specialty fibre for art or crafts, producing } \\
\text { breeding stock for other sheep producers, } \\
\text { providing weed control or pasture } \\
\text { maintenance services, producing milk for } \\
\text { custom cheeses, or simply as a hobby or } \\
\text { a means to introduce children to animal } \\
\text { husbandry. The health of the animals sin } \\
\text { these flocks is important for the animals' } \\
\text { own welfare and to maximise their } \\
\text { productivity to the operator. } \\
\text { A known pathogen with the potential } \\
\text { to damage health and productivity of } \\
\text { sheep is Mycoplasma ovipneumoniae. } \\
\text { This mycoplasma affects respiratory } \\
\text { systems and is transmissible between } \\
\text { fllock members and between flocks, given } \\
\text { animal contacts. Until recently, most } \\
\text { studies were conducted in Europe, Asia } \\
\text { or New Zealand under management } \\
\text { systems with limited relevance to United } \\
\text { States operations. Further, most of the } \\
\text { studies had been conducted using poorly }\end{array}$ & $\begin{array}{l}\text { Professor Tom Besser works as a } \\
\text { research scientist at the Washington } \\
\text { Animal Disease Diagnostic Laboratory } \\
\text { WADDL) at Washington State University } \\
\text { His extensive experience in infectious } \\
\text { disease research perfectly places him } \\
\text { to coordinate the multidisciplinary } \\
\text { team who contributed to this work on } \\
\text { M. ovipneumoniae in domestic sheep } \\
\text { operations. The team includes, Kezia } \\
\text { Manlove of Utah State University, France } \\
\text { Cassirer of Idaho Department of Fish } \\
\text { and Game, and Margaret Benson of the } \\
\text { Washington State University Department } \\
\text { of Animal Science. Their work on the } \\
\text { effects of M. ovipneumoniae infection } \\
\text { in domestic sheep follows logically } \\
\text { from previous work led by Prof Besser } \\
\text { characterising M. ovipneumoniae as } \\
\text { the primary pathogen contributing to } \\
\text { the devastating pneumonia outbreaks } \\
\text { that have limited the recovery of North } \\
\text { American bighorn sheep populations. }\end{array}$ \\
\hline
\end{tabular}

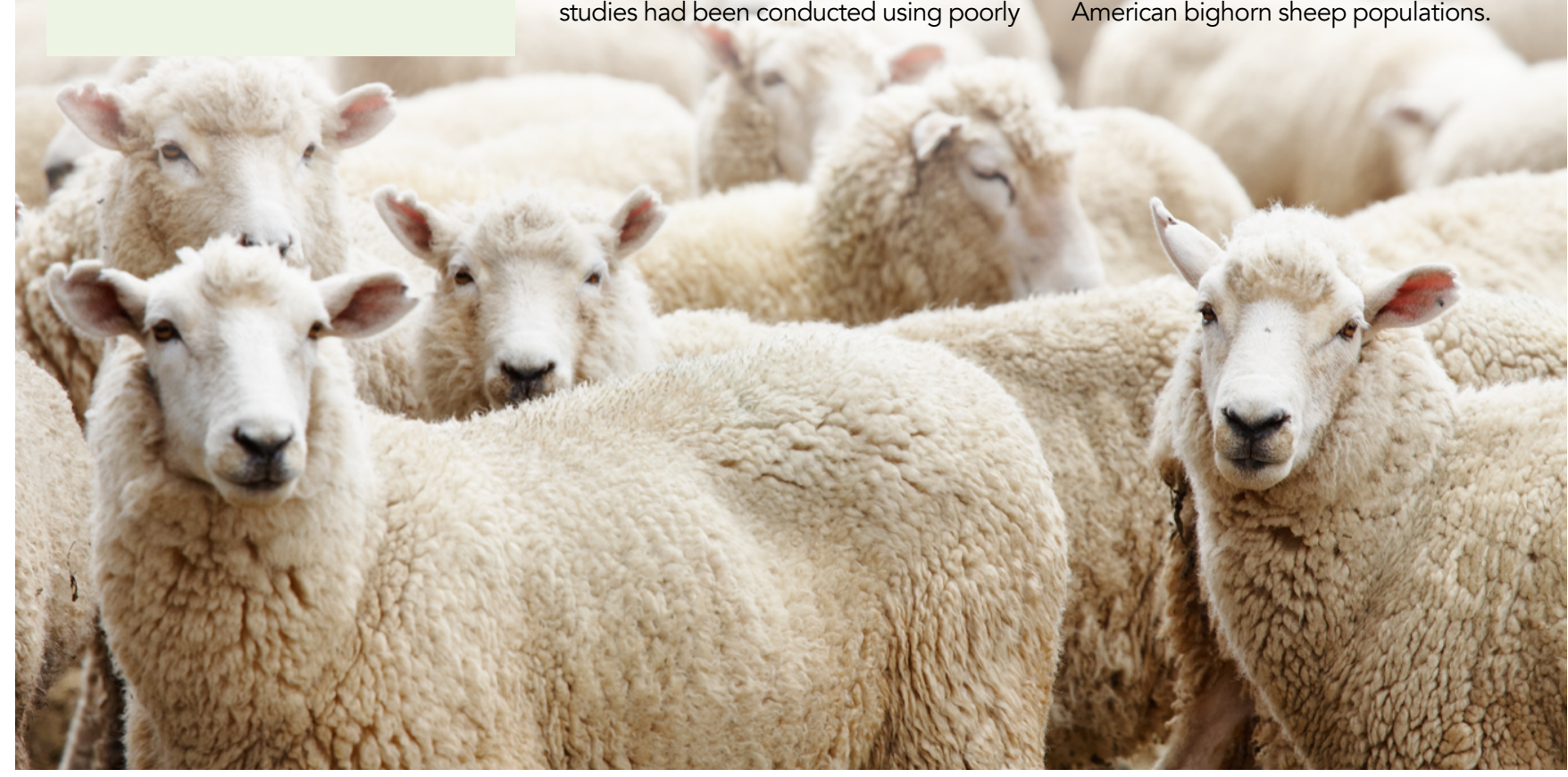
An image of the process of obtaining
a nasal swab from a sheep. Photoc credit

THE SHEEP 2011 PROJECT This work follows a comprehensive evaluation of domestic sheep operations across the country conducted by the U.S. Department of Agriculture entitled 'Sheep 2011 ' In that project, over 450 sheep Q issues pertinent to domestic sheep production and hosted a site visit at which veterinary officers took nasal swab and blood samples from 16 randomly selected ewes for $M$. ovipneumoniae testing at WADDL. Operations at which M.ovipneumoniae was detected by a DNA based test from the nasal swabs, or specific antibodies recognising M.ovipneumoniae were detected in one or more blood samples, were classified as infected. Subsequently, infected and negative operations were compared against five ewe welfare and productivity factors: number of lambs born per ewes bred number of pregnant ewes lambing arviving to weaning weaning and number of sheep dying of respiratory disease.

The Sheep 2011 project team also explored biosecurity-related factors of M.ovipneumoniae infection in the domestic sheep operations. These factors included: operation size; type of operation management; operation biosecurity (rated -1 to 10); overal disease burden (rated 0 to 11 ) and antibiotic use (rated 0 to 5 ).

ANALYSING THE SHEEP 2011 DATA Analysis of the data, including the welfare indicators and the risk factors, led to a of interest to domtic shep operay

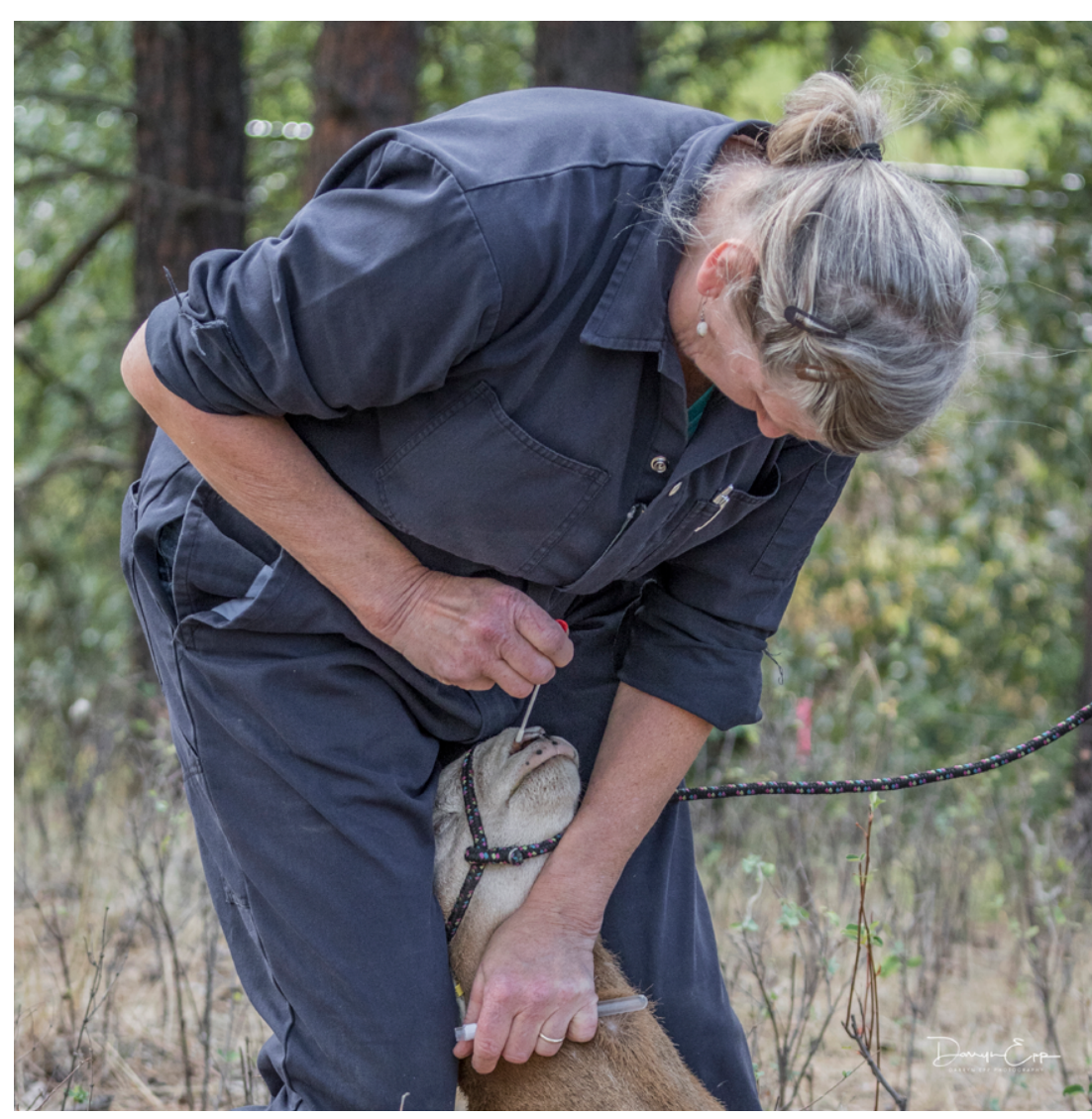

(https://tinyurl.com/NAHMS-Sheep-2011Mo; https://tinyur.com/risk-and-welfare).

Of the 453 farms that participated in the study, $88.5 \%$ tested positive for $M$. ovipneumoniae including all herded operations and more than $85 \%$ of pastured or fenced operations. The operations which tested positive wer signicantly langer than phose which

contribution to respiratory disease in U.S. sheep operations, as has been noted in other countries. However, no association M.ovipneumoniae was observed.

Most specific welfare indicators evaluated in the study were negatively affected by the presence of M. ovipneumoniae. For example, the team found hat birth

Factors which may lead to a domestic sheep operation becoming infected with M.ovipneumoniae include flock size and biosecurity practices.

ewes for positive operations compared to 70 ewes for negative. The trends in type and size of operation across the United States were previously reported by the United States Department of Agriculture. M.ovipneumoniae-positive operations had higher biosecurity risk scores, indicating that careful attention to biosecurity may reduce expostre positive operations hach honiaepositive operations had higher overall still-born lambs was higher in positive significantly affected. These findings were factors affected by M.ovipneumoniae

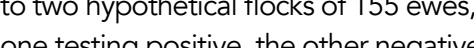
According postive, the other negative. According to the results of this study, the produce 85 femer lositiv herd would produce 8.5 fewer lambs each year, with and $\$ 1,275$. 


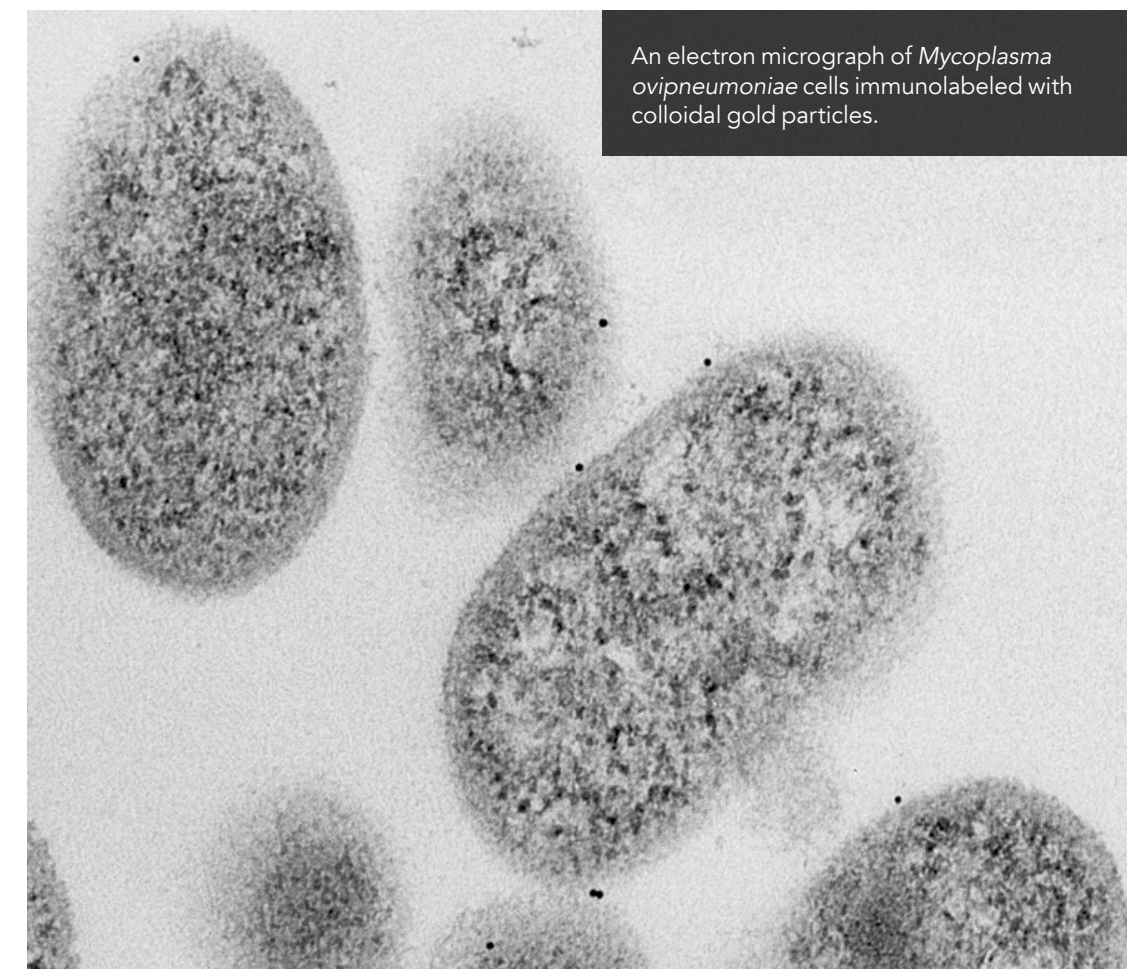

\section{THE LAMB FEEDING}

PILOT PROJECT

Prof Besser and his team also

gains and carcass quality characteristics were compared between the negative and exposed groups.

conducted a pilot study to evaluate the possibility of rearing M.ovipneumoniae negative lambs within a positive flock resulting are the growth of the their M. ovipneumonias exposed flock mates. After three successive nasal

ANALYSING THE LAMB

FEEDING PROJECT DATA

M.ovipneumoniae was not detected in any of the samples obtained from the negative group lambs during feeding or from their lungs at harvest. In contras,

In this first comprehensive study of the extent of M.ovipneumoniae infection in the United States this research has found that more than $85 \%$ of operations are infected.

swab tests conducted over six months, ewes with uniformly M.ovipneumoniaenegative results and their lambs were penned separately from the rest of the 60 days of lambs were weaned at (0 days of age. At weaning, cohor sected from the nere randomly exposed groups and reared separately conder otherwise identical husbandry conditions. Lambs were weighed and tested for M.ovipneumoniae infection they reday intervals until harvested as pounds $(62 \mathrm{~kg})$ : Average daily weight successfully segregating a negative subgroup from within an infected sensitivity of this diagnostic test. In addition the M. ovipneumonia negative lambs produced in this manner showed significantly improved health and productivity, indicating that M.ovipneumoniae infections as found in many domestic sheep operations impose largely silent costs in productivity, and likely also in animal welfare.

\section{A FIRST FOR U.S.}

SHEEP PRODUCTION

The Sheep 2011 data provided the first comprehensive study of the extent Uf M.ovipneumoniae infection in the United States this research has found infected They have identified that this infection prevalence translates to welfare implications for domestic sheep and financial loss for operation owners. The highly sensitive DNA based testing used in these studies documented a greater prevalence of infection than most previous studies conducted in other countries using conventional culture methods. It is important that future research using similar methodology seek to replicate these results under other managemen systems and environmental conditions.

While the authors of these studies found no significant regional differences within the United States, operation size was an important predictor of M.ovipneumoniae infect
rate and it would be extremely
valuable if future research could determine the specific management factors that contribute to the lower infection rate affecting smaller size operations so that these could be applied more broadly to reduce infection prevalence within domestic sheep. The apparent effects of $M$. ovipneumoniae on disease burdens of domestic sheep as well as welfare and productivity metrics support the need for additional research to confirm these adverse associations, and to develop effective management tools to control this previously understudied pathogen. The Lamb Feeding Project demonstrates progress in identifying

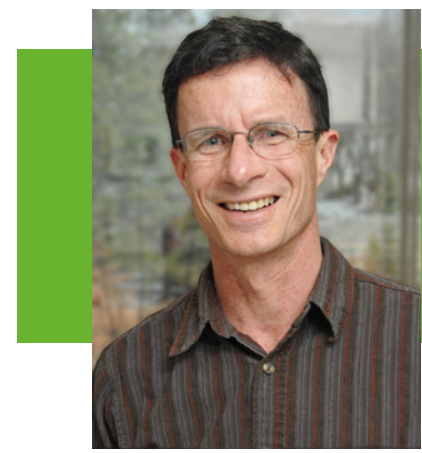

\section{Behind the Research}

\section{Professor Tom Besser}

: tbesser@wsu.edu T: (1) 509-335-6075

Research Objectives

The research of Professor Tom Besser centres on the epidemiology a in domestic and wild sheep.

\section{Detail} his PhD fro University of Minnesota and almost 40 years' research experience into infectious diseases of animals. He has worked for Washington Animal Disease Diagnostic Laboratory since 1990.

\section{Funding}

- United States Department of Agriculture, including the Agricultural Research Service, the Center for Service

The ldaho Department of Fish and Game

- The University of Idaho

- The Wild Sheep Foundation and its state chapters

\section{Collaborators}

Kezia Manlove (Utah State University)

- E. Frances Cassirer (Idaho Department of Fish and Game)

Wenson (Washington State University Dept. of Animal Science)
Professor Tom Besser obtained his Veterinarian

\section{References} Besser TE, Levy J, Ackerman M, Nelson D, Manlove K, Potter
KA, et al. (2019). A pilot study of the effects of Mycoplasma ovipneumoniae exposure on domestic lamb growth and performance. PLOS ONE 14(2): e0207420. https://doi. org/10.1371/journal.pone.0207420

Cassirer, E.F., Manlove, K.R., Almberg, E.S., Kamath, P.L., Cox and Gonzales, B.J. (2018). Pneumonia in bighorn sheep: Ris and resilience. The Journal of Wildlife Management, [online] 82(1), pp.32-45. https://wildlife.onlinelibrary.wiley.com/doi/ $\mathrm{pdf} / 10.1002 / \mathrm{jwmg} .21309$

Manlove, K., Branan, M., Baker, K., Bradway, D., Cassirer, E.F. T.E. (2019). Risk factors and productivity losses associated with Mycoplasma ovipneumoniae infection in United States domestic sheep operations. Preventive Veterinary Medicin lonline] 168, pp.30-38. https://1www.scies
science/article/pii/S0167587718304446

\section{Personal Response}

\section{Are there opportunities for studies into other} domestic animal production operations to use the What do you enisege the long yourm impact of this

II The data from these projects offer intriguing clues that M. ovipneumoniae may present domestic sheep significant respiratory disease is not observed These findings merit follow up studies: How much do the adve effects scale with prevalence of the pathogen? Are these effects general across genetic strains of the pathogen, or are some genotypes more virulent than others? What

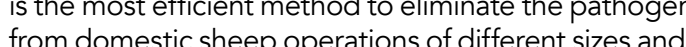
management systems ff the pathogen is eliminated what level of biosecurity is required to keep it out?

College of Veterinary Medicine 